\title{
Primary Graviceptive System and Astasia: Case Report and Literature Review
}

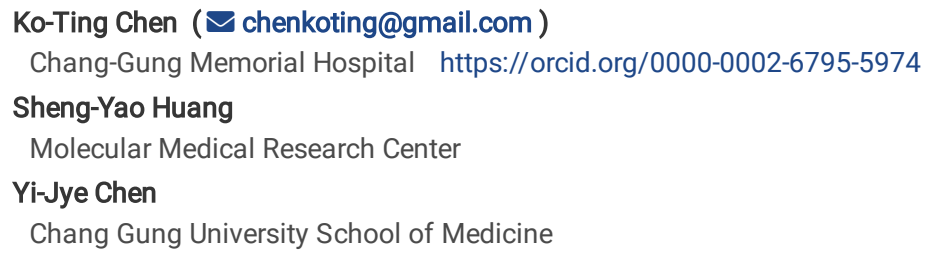

Keywords: astasia, graviceptive system, subjective visual vertical, subjective posture vertical, thalamo-cortical projections, vestibule-thalamic pathway

Posted Date: November 12th, 2021

DOI: https://doi.org/10.21203/rs.3.rs-833382/v1

License: (c) (i) This work is licensed under a Creative Commons Attribution 4.0 International License. Read Full License 


\section{Abstract}

\section{Purpose of Review}

Astasia refers to the inability to maintain upright posture during standing, despite having full motor strength. However, the pathophysiology and neural pathways of astasia remains unclear.

\section{Recent Findings}

We analyzed 26, including ours, non-psychogenic astasia patients in English literature. Seventy-three percent of them were man, $73 \%$ were associated with other neurologic symptoms and $62 \%$ of reported lesions were at right side. Contralateral lateropulsion was very common followed by retropulsion while describing astasia. Infarction (54\%) was the most commonly reported cause. Thalamus (65\%) was the most commonly reported location. Infarction being the mostly likely to recover (mean:10.6 days), while lesions at brainstem had longer time to recover (mean: 61.6 days).

\section{Summary}

The underlying interrupted pathway may be the primary graviceptive system, which composed of at least five unilateral and contralateral projection fibers from vestibular nuclei to thalamic nuclei, and thalamo-cortical projections including subcortical white matter tracts and cortical areas.

\section{Key Points}

1. Astasia may be caused by an interruption of primary vestibular system and its thalamocortical projections.

2. Contralateral lateropulsion is the most common symptom of astasia when lesions affect level higher than pontomesencephalic junction.

3. Infarction is the most common cause, yet has best recovery, of non-psychogenic astasia, followed by hemorrhage and tumor.

4. Lesions causing astasia from brainstem have longer recovery period than in lesions in thalamus, subcortical white matter, and cortical regions.

5. Patients with astasia and pusher syndrome have different symptomatology, different perception of visual vertical, therefore, may be affected by different thalamocortical pathways projected from posterior thalamus.

\section{Introduction}

Astasia refers to the inability to maintain upright posture during standing, despite having full motor strength in four limbs. ${ }^{25}$ There are no or minimal associated abnormalities in neurological examination other than gait disturbance and truncal instability. It was once recognized as a psychogenic or conversion disorder ${ }^{27}$, however, organic causes have engrossed this term in recent years. Several regions have been reported to be responsible for astasia, including mesencephalon $5,24,32$, thalamus ${ }^{10,22,25}$, suprathalamic white matter ${ }^{33}$, corpus callosum (CC) ${ }^{37}$, cingulate gyrus ${ }^{16,31,37}$, and supplementary motor $(\mathrm{SMA})^{35}$. The causes are not limited to stroke $\mathrm{e}^{5,10,16,22,24,25,29,31-33,35,37}$, but also tumor ${ }^{25}$, inflammatory disease ${ }^{36}$ and hyper-perfusion ${ }^{18}$. The pathophysiology and neural pathways of astasia remains largely unknown.

We describe a patient with butterfly glioblastoma involving body of CC and bilateral periventricular white matter, who had isolated astasia-abasia as initial presentation. After nearly total removal of the tumor, he regained posture stability and balance partially with the help of rehabilitation. To discuss the pathomechanisms of astasia, all reported cases with astasia were reviewed. We propose the primary graviceptive system, a network to maintain body upright posture, being the underlying network results in astasia when interrupted.

\section{Text Of Review}

\subsection{Case Illustration}

\section{Preoperative evaluation}

A written informed consent was given to the patient for this study. The 50-year-old man is a right-handed worker who presented with acute onset of gait unsteadiness for 2 weeks progressively. He was unable to stand straight on his own. When asked to sit up, he would grasp the side rail of the bed with both hands to pull himself up, without using axial muscles. When trying to walk under assistance, his base of gait was inconstant and unstable and he easily fell toward either side or backwardly. However, his muscle power was grade $5 / 5$ during supine position and deep tendon reflex was normal, not suggesting any peripheral neuropathy. Romberg's test couldn't be performed and finger-nose-finger test showed no dysmetria. He was fully orientated but apathetic appearance. There was no cranial nerve deficit. Sensory function was intact. Other accompanying symptoms included dizziness, nausea, and short memory decline. The above symptoms suggested a clinical diagnosis of an isolated astasia-abasia. Magnetic resonance imaging (MRI) showed two separate lesions (Figure $1 \mathrm{~A}-\mathrm{C})$, including a butterfly pattern intra-axial mass $(6 \mathrm{~cm})$, involving body of $\mathrm{CC}$, septum pellucidum and body of fornix.

\section{Surgical resection}

Right frontal tumor was firstly removed after somatosensory evoked potential to confirm the primary motor cortex was behind the tumor. Then, a combined right transfrontal and bilateral interhemispheric approach was performed under a neurophysiologic monitoring of triggered motor evoked potential during removal of tumors with high signal intensity on T2-WI. At the end of resection, bilateral lateral ventricle was entered, fornix was invaded by the tumor which 
was partially resected and body of third ventricle was under direct vision. The pathology of right frontal lesion was a diffuse astrocytoma, IDH-mutant, WHO grade 2; and the tumor at CC was a glioblastoma, IDH-mutant. A postoperative MRI showed a complete removal of CC tumor (Figure 1D-F).

\section{Postoperative Clinical Course}

The patient had a transient left side weakness with a muscle power of grade 4-and left central type facial palsy, which completely recovered within postoperative 2 weeks. After intensive rehabilitation, a gradual, but significant, improvement of his sitting balance, posture control was noted. Six months later, though activity of daily life was still partially dependent, he was able to stand upright and walk under assistance, suggesting a partial recovery of astasiaabasia even after an extensive removal of body of CC.

\subsection{Literature review}

To review the reported studies, a keyword "astasia" was used to search on Pubmed, Google Scholar searching engines. Topics related to psychogenic astasia or physical therapy for astasia, and cases caused by inflammatory disease or toxic encephalitis were excluded. A total of 15 studies of organic astasia were included for a second review. Two reports in French ${ }^{4,20}$, one report stated the patient did not fell during attack ${ }^{17}$ (astasia unlikely) and another one with only abstract available ${ }^{21}$ were further excluded. Finally, clinical, imaging and pathophysiological information for the 26 patients, including ours, in 12 studies $^{5,10,16,22,24,25,31-33,35,37}$ were collected and analyzed systemically. Time to recovery was defined by the description that a patient was able to stand or walk independently or with minimal assistance. A partial recovery was defined as the patient need assistance to stand or walk. An IBM ${ }^{\circledR}$ SPSS ${ }^{\circledR}$ Statistics version 20.0 was used for statistical analysis. Independent Student $t$ test was used for scale variables. A statistical significance was defined as $p$ value $<0.05$.

\subsection{Results}

Table 1 summarized all non-psychogenic astasia patients reported in English literature from 1976 to 2019. The demographic data, associated symptoms, mechanism and laterality of astasia, proposed affected pathway and the recovery period of astasia were shown. A total of 26 patients, including ours, were categorized in order of location of lesions from brainstem, thalamus, cerebral white matter and cortex. The intention was to give a virtual illustration of the involved projection fibers responsible to astasia. 
Table 1

Summary of all reported nonpsychogenic astasia-abasia patients in English literature from 1976-2019 ( $\mathrm{n}=26)$

\begin{tabular}{|c|c|c|c|c|c|c|c|c|c|}
\hline Author & $\begin{array}{l}\text { Case } \\
\text { num. }\end{array}$ & $\begin{array}{l}\text { Age(yr) } \\
\text { / Sex }\end{array}$ & $\begin{array}{l}\text { Associated } \\
\text { symptomst }\end{array}$ & $\begin{array}{l}\text { Laterality of } \\
\text { pulsion }\end{array}$ & Causes & Location & $\begin{array}{l}\text { Laterality } \\
\text { of lesion }\end{array}$ & $\begin{array}{l}\text { Proposed affected } \\
\text { pathway } \$\end{array}$ & $\begin{array}{l}\text { Recovery } \\
\text { of astasia } \\
\text { (days) }\end{array}$ \\
\hline $\begin{array}{l}\text { Masdeu, } \\
1994\end{array}$ & 1 & 83 / M & $\begin{array}{l}\text { Up-gaze } \\
\text { palsy }\end{array}$ & Retropulsion & Hemorrhage & $\begin{array}{l}\text { Pontomesencephalic } \\
\text { junction (DM) }\end{array}$ & $\mathrm{R}$ & $\begin{array}{l}\text { Vestibulocerebellar } \\
\text { pathway }\end{array}$ & $\begin{array}{l}>120 \\
\text { (partial) }\end{array}$ \\
\hline $\begin{array}{l}\text { Song, } \\
2007\end{array}$ & 1 & 70 / M & Asterixis & $\begin{array}{l}\mathrm{CL} \\
\text { lateropulsion } \\
\text { or } \\
\text { retropulsion }\end{array}$ & Infarction & $\begin{array}{l}\text { Medial thalamo- } \\
\text { mesencephalic }\end{array}$ & $\mathrm{L}$ & $\begin{array}{l}\text { Vestibulocerebellar } \\
\text { pathway }\end{array}$ & 5 \\
\hline $\begin{array}{l}\text { Pablo- } \\
\text { Fernandez, } \\
2009\end{array}$ & 1 & 58 / M & $\begin{array}{l}\text { Gaze palsy, } \\
\text { asterixis }\end{array}$ & $\begin{array}{l}\mathrm{CL} \\
\text { lateropulsion } \\
\text { or } \\
\text { retropulsion }\end{array}$ & Hemorrhage & $\begin{array}{l}\text { Medial thalamo- } \\
\text { mesencephalic }\end{array}$ & $\mathrm{R}$ & $\begin{array}{l}\text { Vestibulocerebellar } \\
\text { pathway }\end{array}$ & 60 \\
\hline \multirow[t]{3}{*}{$\begin{array}{l}\text { Masdeu, } \\
1988 \S\end{array}$} & 7 & $\begin{array}{l}65.4 / \\
6 \mathrm{M}, 1 \mathrm{~F}\end{array}$ & $\begin{array}{l}\text { Sensory } \\
\text { deficits }\end{array}$ & $\begin{array}{l}\mathrm{CL} \\
\text { lateropulsion } \\
\text { or } \\
\text { retropulsion }\end{array}$ & Hemorrhage & Thalamus (dorsal*) & $4 \mathrm{R}, 3 \mathrm{~L}$ & $\begin{array}{l}\text { Vestibulocerebellar } \\
\text { pathway }\end{array}$ & $\begin{array}{l}21.7 \\
\text { (mean) }\end{array}$ \\
\hline & 6 & $\begin{array}{l}73.6 / \\
3 \mathrm{M}, 3 \mathrm{~F}\end{array}$ & $\begin{array}{l}\text { Sensory } \\
\text { deficits }\end{array}$ & & Infarction & Thalamus $\left(\mathrm{VL}^{\ddagger}\right)$ & $4 \mathrm{R}, 2 \mathrm{~L}$ & & 4.6 (mean) \\
\hline & 2 & $\begin{array}{l}60.5 / \\
1 \mathrm{M}, 1 \mathrm{~F}\end{array}$ & $\begin{array}{l}\text { Sensory } \\
\text { deficits }\end{array}$ & & Tumor & $\begin{array}{l}\text { Thalamus } \\
(\mathrm{AL}, \mathrm{VB})\end{array}$ & $2 \mathrm{R}$ & & Progressive \\
\hline Lee, 2005 & 1 & $76 / F$ & $\begin{array}{l}\text { Sensory } \\
\text { deficit }\end{array}$ & $\begin{array}{l}\text { Antepulsion } \\
\text { or } \\
\text { retropulsion }\end{array}$ & Infarction & Thalamus (PL) & $\mathrm{R}$ & $\begin{array}{l}\text { Second } \\
\text { graviceptive } \\
\text { pathway }\end{array}$ & 2 \\
\hline $\begin{array}{l}\text { Elwischger, } \\
2011\end{array}$ & 1 & 82 / M & None & $\begin{array}{l}\mathrm{CL} \\
\text { lateropulsion }\end{array}$ & Infarction & Thalamus (CM) & $\mathrm{L}$ & $\begin{array}{l}\text { Crossed } \\
\text { graviceptive } \\
\text { pathway }\end{array}$ & 42 \\
\hline $\begin{array}{l}\text { Takahashi, } \\
2016\end{array}$ & 1 & 73 / F & None & Retropulsion & Infarction & $\begin{array}{l}\text { Suprathalamic white } \\
\text { matter }\end{array}$ & $\mathrm{R}$ & $\begin{array}{l}\text { Thalamo-cortical } \\
\text { projection }\end{array}$ & 4 \\
\hline $\begin{array}{l}\text { Chen, } \\
2019 \text { - } \\
\text { present } \\
\text { case }\end{array}$ & 1 & 50 / M & None & $\begin{array}{l}\text { Retropulsion } \\
\text { or either } \\
\text { sides }\end{array}$ & Tumor & $\begin{array}{l}\text { Corpus callosum } \\
\text { body }\end{array}$ & Bil & $\begin{array}{l}\text { Thalamo-cortical } \\
\text { pathway, bil }\end{array}$ & $\begin{array}{l}>180 \\
\text { (partial) }\end{array}$ \\
\hline $\begin{array}{l}\text { Zhang, } \\
2015\end{array}$ & 1 & $65 / M$ & None & $\begin{array}{l}\mathrm{CL} \\
\text { lateropulsion, } \\
\text { retropulsion }\end{array}$ & Infarction & $\begin{array}{l}\text { Anterior cingulate, } \\
\text { corpus callosum }\end{array}$ & $\mathrm{R}$ & $\begin{array}{l}\text { Vestibulocerebellar } \\
\text { pathway; } \\
\text { disconnection }\end{array}$ & 30 \\
\hline $\begin{array}{l}\text { Kataoka, } \\
2006\end{array}$ & 1 & $67 / M$ & None & $\begin{array}{l}\mathrm{CL} \\
\text { lateropulsion }\end{array}$ & Infraction & Posterior cingulate & $\mathrm{L}$ & $\begin{array}{l}\text { Cingulate motor } \\
\text { area }\end{array}$ & 14 \\
\hline $\begin{array}{l}\text { Satow, } \\
2014\end{array}$ & 1 & $58 / M$ & None & $\begin{array}{l}\mathrm{CL} \\
\text { lateropulsion }\end{array}$ & Infarction & Middle cingulate & $\mathrm{L}$ & $\begin{array}{l}\text { Cingulate motor } \\
\text { area }\end{array}$ & 21 \\
\hline $\begin{array}{l}\text { Wada, } \\
2010\end{array}$ & 1 & $61 / M$ & None & $\begin{array}{l}\mathrm{CL} \\
\text { lateropulsion }\end{array}$ & Infarction & $\begin{array}{l}\text { Supplementary } \\
\text { motor area }\end{array}$ & $\mathrm{R}$ & $\begin{array}{l}\text { Vestibulocerebellar } \\
\text { pathway }\end{array}$ & 2 \\
\hline
\end{tabular}

A: anterior; AL: anterolateral; Bil: bilateral; CL: contralateral; CM: centromedian; DM: dorsomedial; F: female; L: left; M: male; N/A: not available; PL: posteriolateral; R: right; VB: ventrobasal; VL: ventrolateral

†Associated symptoms were defined as neurological deficits described in the study.

$\$$ All affected pathways proposed in each study were recorded, and a summary was made after a detailed discussion and literature review.

'Time to recovery was defined by the description that a patient was able to stand or walk independently or with minimal assistance. A partial recovery was defined as the patient need assistance to stand or walk.

*According to Masdeu et al., dorsal4, dorsoposteriorlateral*1, dorsomedial*1, and lateral¹.

${ }^{\ddagger}$ According to Masdeu et al., ventrolateral*4, suprathalamic*1 and only anteriomedial spared*1.

$\S$ Age and recovery period were presented as mean. 


\begin{tabular}{|c|c|c|c|c|c|c|c|c|c|}
\hline Author & $\begin{array}{l}\text { Case } \\
\text { num. }\end{array}$ & $\begin{array}{l}\text { Age(yr) } \\
\text { / Sex }\end{array}$ & $\begin{array}{l}\text { Associated } \\
\text { symptoms } †\end{array}$ & $\begin{array}{l}\text { Laterality of } \\
\text { pulsion }\end{array}$ & Causes & Location & $\begin{array}{l}\text { Laterality } \\
\text { of lesion }\end{array}$ & $\begin{array}{l}\text { Proposed affected } \\
\text { pathway } \$\end{array}$ & $\begin{array}{l}\text { Recovery } \\
\text { of astasia } \\
\text { (days) }\end{array}$ \\
\hline Summary & 26 & $\begin{array}{l}67.8 / \\
19 \mathrm{M} \\
7 \mathrm{~F}\end{array}$ & $\begin{array}{l}19 \text { with and } \\
7 \text { without } \\
\text { associated } \\
\text { symptoms }\end{array}$ & $\begin{array}{l}\mathrm{CL} \\
\text { lateropulsion } \\
\text { and } \\
\text { retropulsion }\end{array}$ & $\begin{array}{l}\text { Infarction(14), } \\
\text { hemorrhage } \\
\text { (9), tumor (3) }\end{array}$ & $\begin{array}{l}\text { Brainstem (3), } \\
\text { thalamus (17), } \\
\text { White matter (2), } \\
\text { cortex (4) }\end{array}$ & $\begin{array}{l}\mathrm{R}(16), \\
\mathrm{L}(9) \\
\text { Bil (1) }\end{array}$ & $\begin{array}{l}\text { Primary } \\
\text { graviceptive } \\
\text { system \& thalamo- } \\
\text { cortical projections } \\
\text { See "Discussion" }\end{array}$ & $\begin{array}{l}32.7 \\
\text { (mean) } \\
\text { Total: } 16.4 \\
\text { Partial: } \\
>160\end{array}$ \\
\hline
\end{tabular}

A: anterior; AL: anterolateral; Bil: bilateral; CL: contralateral; CM: centromedian; DM: dorsomedial; F: female; L: left; M: male; N/A: not available; PL: posteriolateral; R: right; VB: ventrobasal; VL: ventrolateral

†Associated symptoms were defined as neurological deficits described in the study.

$\$$ All affected pathways proposed in each study were recorded, and a summary was made after a detailed discussion and literature review.

'Time to recovery was defined by the description that a patient was able to stand or walk independently or with minimal assistance. A partial recovery was defined as the patient need assistance to stand or walk.

*According to Masdeu et al., dorsal*4, dorsoposteriorlateral*1, dorsomedial*1, and lateral*1.

${ }^{\ddagger}$ According to Masdeu et al., ventrolateral*4, suprathalamic* 1 and only anteriomedial spared* 1 .

$\S$ Age and recovery period were presented as mean.

In these 26 patients, there were 19 men and 7 women with a mean age of 67.8 years. Nineteen (73\%) reported cases, all located at brainstem or thalamus, had associated symptoms, including gaze palsy, asterixis and sensory deficits. Specifically, the characters of laterality of pulsion movement were reviewed, and most cases reported contralateral lateropulsios or retropulsions. Infarction, hemorrhage and tumor were three causes reported in non-psycogenic astasia, fourteen of whom (54\%) were due to infarction, nine of whom (35\%) were due to hemorrhage and 3 of whom (11\%) were due to tumor. For location of lesions, three patients $(11 \%)$ in brainstem, seventeen patients $(65 \%)$ in thalamus, two patients ( $8 \%)$ in cerebral white matter, and 4 patients $(15 \%)$ in cerebral cortex. Sixteen patients $(62 \%)$ had their lesions on the right side, nine patients (35\%) on the left side, and 1 patient had a bilateral lesion (our case). For the affected pathway, a comprehensive discussion is made in the discussion paragraph. Despite various causes, only 4 cases did not recovered well, three of whom were caused by tumor (two in Masdeu's series ${ }^{24}$ and our case); while 22 cases (85\%) were considered recovery (patients were able to stand or walk independently or with minimal assistance) with a mean duration of 16 days.

Table 2 analyzed time to recovery of astasia by different causes. A trend toward sooner recovery caused by infarction than by hemorrhage was found, with a mean time to recovery of 10.6 days comparing to that of 36.9 days in hemorrhagic cause $(p=0.058)$. There were 3 patients, including ours, caused by a tumor, however, 2 patients with thalamic tumor reported by Masdeu ${ }^{25}$ did not received treatment and astasia progressed without recovery.

Table 2

Analysis of time to recovery of astasia by causes $(n=26)$

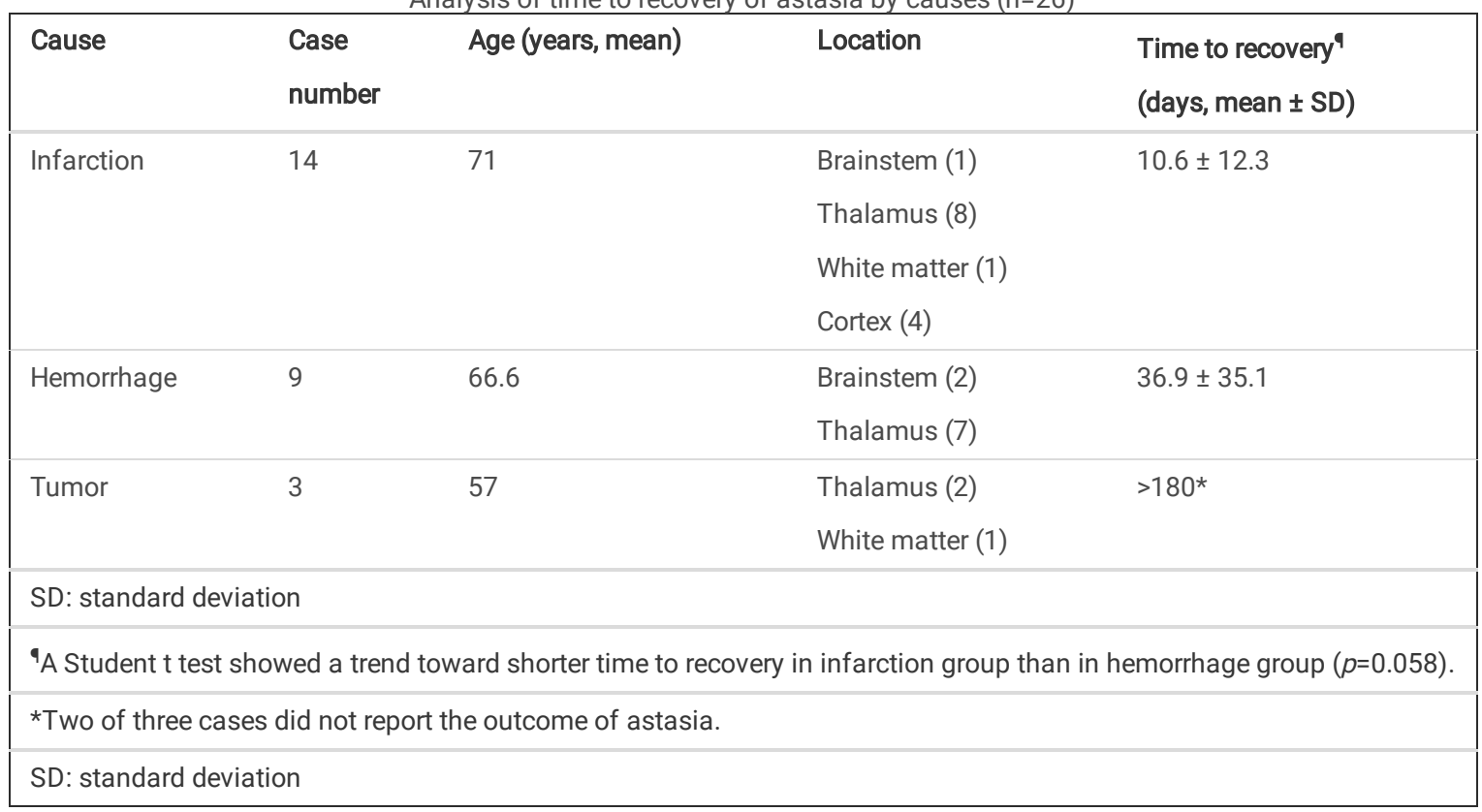


Table 3 analyzed time to recovery of astasia by different locations. The averaged time to recovery was 61.6 days in brainstem group, 14.9 days in thalamus group, 92 days in cerebral white matter group, and 16.5 days in cortex group. A statistically significant longer time to recovery when lesion was in brainstem than in thalamus $(p=0.007)$; while no difference was found when comparing lesions in thalamus to lesions in cortex $(p=0.306)$.

Table 3

Analysis of time to recovery of astasia by lesion locations $(n=26)$

\begin{tabular}{|c|c|c|c|c|}
\hline Location & $\begin{array}{l}\text { Case } \\
\text { number }\end{array}$ & Age (years, mean) & Cause & $\begin{array}{l}\text { Time to recovery } \\
\text { (days, mean } \pm \text { SD) }\end{array}$ \\
\hline Brainstem & 3 & 70.3 & $\begin{array}{l}\text { Hemorrhage (2), } \\
\text { Infarction (1) }\end{array}$ & $>61.6 \pm 57.5$ \\
\hline Thalamus & 17 & 69.4 & $\begin{array}{l}\text { Hemorrhage (7), } \\
\text { Infarction (8), } \\
\text { Tumor (2) }\end{array}$ & $14.9 \pm 13.9 *$ \\
\hline Cerebral whit matter & 2 & 61.5 & $\begin{array}{l}\text { Infarction (1) } \\
\text { Tumor (1) }\end{array}$ & $>92$ \\
\hline Cortex & 4 & 62.8 & Infarction (4) & $16.5 \pm 11.9$ \\
\hline
\end{tabular}

SD: standard deviation

'A Student $t$ test showed a statistically significant longer time to recovery when lesion was in brainstem than in thalamus ( $p=0.007)$; while no difference was found when comparing lesions in thalamus to lesions in cortex $(p=0.306)$.

*Two cases caused by tumor were excluded for time to recovery analysis, since these two patients progressed rather than recovered.

In sum, we summarized and analyzed all 26 non-psychogenic astasia patients in English literature. Seventy-three percent of them were man ( $\mathrm{n}=19)$, $73 \%$ were associated with other neurologic symptoms $(n=19)$ and $62 \%$ of reported lesions were at right side $(n=16)$. Contralateral lateropulsion was very common followed by retropulsion while describing astasia. Infarction was the most commonly reported cause ( $n=14,54 \%)$. Thalamus was the most commonly reported location $(n=17,65 \%)$. An association between cause of astasia and time to recovery was found, infarction being the mostly likely to recover with a mean of 10.6 days. Lesions at brainstem had longer time to recover with a mean of 61.6 days.

\subsection{Discussion}

By characterizing of pulsion movements and the proposed pathways, including vestibulocerebellar pathway, graviceptive pathway and cingulate motor area (CMA), we aim to elucidate the underlying neural network through discussing the meaning lateropulsion and the possible commonality among these pathways. A seminal paper by Masdeu ${ }^{25}$ firstly reported a series of thalamic astasia, and has discussed in detail to differentiate astasia from on other causes of the abnormality of gait and station, such as cerebellar dysmetria, thalamic akinesia, sensory impairment, and hyperekplexia. ${ }^{25} \mathrm{~A}$ bilateral projections of vestribulocerebellar pathway from fastigial nucleus was initially proposed to explain the affected pathway at the level thalamus and to explain the transient nature of thalamic astasia. ${ }^{25}$ Since then, majority of reported cases adopted the concept in lesions from brainstem to cortical regions. ${ }^{5,24,32,35,37}$ Apart from this, impairment of graviceptive systems have been reported in patients with thalamic infarct at centromedian nucleus ${ }^{10}$ and posterolateral nucleus ${ }^{22}$, respectively. Lesions above thalamus distributed widely from suprathalamic white matter ${ }^{33}$, corpus callosum (our case) to cingulate gyrus ${ }^{16,31,37}$ and SMA ${ }^{35}$; and in these cases, a disturbance of CMA ${ }^{16,31}$ and thalamo-cortical projections ${ }^{33}$ were considered. In essence, a cerebello-vestibulo-thalamic-cortical pathway may be involved in generating astasia, however, the connection and neural network between these speculated pathways remained unclear.

\section{Graviceptive systems: vestibule-thalamic projections}

The linkage between astasia and vestibule-thalamic pathways clearly declares the associated network is in the vestibular system, which has a unique role in sensorimotor control and perception. ${ }^{23}$ Multiple thalamic nuclei are incorporated in vestibular processing, including the ventroposterior complex, the ventroanterior-ventrolateral complex, the intralaminar nuclei and the posterior nuclear group (medial and lateral geniculate nuclei, pulvinar). ${ }^{23}$ Specifically, posterolateral thalamic lesions may present tilt of the perceived visual vertical ${ }^{2,3}$ and postural instability ${ }^{15,14}$. Therefore, by relaying vestibular cues, and particularly graviceptive cues, this thalamic region could be involved in encoding gravity and controlling body orientation in space. ${ }^{23}$ Subjective visual vertical (SVV) tilts are the most sensitive sign of a vestibular tone imbalance in roll and occur with peripheral or central vestibular lesions from the labyrinthine to the vestibular cortex. ${ }^{2}$ Two graviceptive systems have been introduced, the primary graviceptive system, perception of visual world, is characterized by a SVV tilt either ipsiversively (ipsilateral eye undermost) or contraversively (contralateral eye undermost). ${ }^{2}$ Two neural pathways identified responsible for these tilt symptoms, (1) a crossed graviceptive pathway involving the medial longitudinal fasciculus to the interstitial nucleus of Cajal may results in ipsi- or contraversive tilt depending on location of the lesion ${ }^{2}$; and (2) an ipsilateral graviceptive pathway running from vestibular nuclei close to and within the medial lemniscus to the posterolateral thalamus results in only ipsiversive tilt. ${ }^{38}$ 
The second graviceptive system proposed by Karnath et al. locates in posterior thalamus, therefore argued this area as being not only a "first-order relay structure" of the vestibular pathway ${ }^{13,14}$, but a "higher order" relay station. ${ }^{11}$ They have described a symptom named "contraversive pushing" or "pusher syndrome" presented in patients with thalamic stroke. When at rest and also when asked to sit up, pusher patients extend the unaffected arm and use it to push away actively from the nonparetic side. ${ }^{13}$ Moreover, pusher patients experienced their body as oriented "upright" when the subjective postural vertical (SPV) was tilted $18^{\circ}$ to the nonhemiparetic, ipsilesional side. In contrast, perception of the SVV was undisturbed. ${ }^{14}$ Both pusher syndrome and astasia are disturbances in controlling of upright body posture and involve posterior thalamus. Nevertheless, they seem to be different in several aspects: first, astasia patients had minimal or no weakness of muscle power, while pusher patients were hemiparetic. Second, astasia patients presented with contralateral lateropulsion, which fell "without" a push from either side of extremity, while pusher patients had their nonparetic arm push away "actively" from nonparetic side (fell contralaterally). Third, and probably the most distinctive one, is that astasia patients perceived tilted SVV",3,8,9, while pusher patients perceived a severe ipsiversive tilted SPV with SVV undisturbed. ${ }^{10,13-15}$ However, one may argue that no SPV data has been reported in astasia patients. In addition, it has been demonstrated that the possible cortical network of the second graviceptive system includes inferior frontal gyrus, middle temporal gyrus, inferior parietal lobule and parietal white matter, by showing hypoperfusion in this regions. ${ }^{34}$ This pattern of cortical areas provides indistinguishable information from the primary graviceptive system, which was primarily considered project to parietal-insular vestibular cortex (PIVC). ${ }^{2}$ Although anatomically overlapped, a functional discrepancy has already been suggested that the perceived relation of the visual world to the vertical is exclusively determined by sense organs in the head, whereas body posture is also directly measured by recently discovered graviceptors in the human trunk. ${ }^{26}$

We now inspect the phenomenon of body lateropulsion. Since this is presented in nearly all reported patients with astasia, body lateropulsion may be considered a physical biomarker for astasia. From a review by Dieterich et al., it has been shown that lesions involving a caudal medullary lesion of the spinocerebellar tract, the descending lateral vestibulospinal tract, the ascending vestibulo-thalamic and dentatorubro-thalamic pathways, or the thalamocortical fascicle were associated with lateropulsions. ${ }^{8}$ The majority of reported cases with isolated symptomatology of lateropulsion were attributed to lesions in the brainstem, e.g. Wallenberg syndrome ${ }^{8,18}$, despite rare, we have added not a few cases from different anatomical locations with body lateropulsion in this review. In our opinion, the evidences seem guide us to the primary graviceptive system as the responsible pathways, including ipsilateral vestibulothalamic pathway and crossed vestibulothalamic pathway, for astasia. Afterwards, two anatomically distinct graviceptive signal processing systems within the thalamus, which resulted in contra- or ipsi-versive tilt of SVV, have been elucidated. ${ }^{1}$

\section{Thalamo-cortical projections: subcortical white matters}

A wide and extensive network interconnection has been delineated between thalamus and multiple "vestibular cortex" areas in the primary graviceptive pathways. ${ }^{7,19}$ Not two but five separate and distinct vestibular pathways were identified thereafter: three run ipsilaterally, while the two others cross either in the pons or the midbrain. Two of the ipsilateral projections run through the posterolateral or paramedian thalamic subnuclei, while the third bypasses the thalamus to reach the inferior part of the insular cortex directly. Both contralateral pathways travel through the posterolateral thalamus. ${ }^{19}$ At the cortical level, the PIVC regions of both hemispheres with a right hemispherical dominance are interconnected transcallosally through the antero-caudal splenium. ${ }^{19}$ In our case and one case presented by Zhang et al. ${ }^{37}$, corpus callosum has been involved. However, it was our case that involve the whole body of CC from genu to splenium. We believe this explains why in our patient astasia could improve partially, owing to a significantly reduced mass effect on subcortical white matter pathway bilaterally after surgery and adjuvant therapies, but never fully, owing to a loss of connectivity between bilateral hemispheric vestibular pathways. We also believe, aside from the bilaterally projected fastigial outputs, a bi-hemispheric compensation of vestibular function via transcallosal communication contributes a rapid recovery of a balanced upright posture in both infarction and hemorrhage related astasia patients in the literature.

\section{Thalamo-cortical projections: cortical level}

It has been summarized that apart from PIVC, there were vestibular responses recorded in the somatosensory cortex, intraparietal sulcus, posterior parietal cortex, medial superior temporal area, frontal cortex (primary motor and SMA), cingulum and hippocampus. ${ }^{23}$ Cingulate motor areas, enfold in cingulate sulcus, have been studied primarily in nonhuman primates ${ }^{12,30}$, even so a human evidence has been provided by a real-time motor representation using subdural electrode recording. ${ }^{6}$ A significant corticocortical interconnection between SMA, frontal eye field, motor cortex and CMAs represents its function in movement initiation and modification. ${ }^{6,12,28,30}$ Therefore, cingulum, not only CMAs, has abundant connectivity which are subtended by pathways running from thalamus as well as intercortical areas. All in all, the vestibular system, composed of graviceptive system (vestibule-thalamic pathways) and thalamo-cortical projections, adequately clarify all reported astasia patients in literature. Interestingly, all reported cortical regions were along medial hemispheric surface, such as cingulate gyrus and SMA (Table1 and Figure 2). Whether the regional preference has its biological significance or not remained to be determined.

There are limitations of this study. First, a publication bias and selection bias is inevitable, since we selected only reports used "astasia" in topic from literature. On the other side, we may only understand better the pathophysiology of astasia through these selected representative cases. Second, one should be aware that lesions affecting pathways associated with astasia might be more common than reported, however, more damages result in serious symptoms may mask astasia from clinical detection. Third, this being a retrospective review could only provide a correlation analysis between a known deficit and proposed pathways. For such a rare symptom, despite difficulty, a larger patient cohort or delicate imaging examinations may be needed to validate our findings.

\section{Conclusion}

In conclusion, we summarize that astasia always presents with lateropulsion of body; and the underlying interrupted pathway may be the primary graviceptive system, which composed of at least five unilateral and contralateral projection fibers from vestibular nuclei to thalamic nuclei, and thalamo-cortical projections including subcortical white matter tracts and cortical areas. Future study on astasia should include SVV and SPV to elucidate the pathological 
changes of perception of verticality in the visual world and the body. A symptomatology or electrical stimulation comparative study of controlling body posture on medial hemispheric versus lateral hemispheric vestibular cortices may help to understand the differences between these areas.

\section{Abbreviations}

CC: corpus callosum; CMA: cingulate motor area; IDH: isocitrate dehydrogenase; MRI: magnetic resonance imaging; PIVC: parietal insular vestibular cortex; SMA: supplementary motor area; SPV: subjective postural vertical; SVV: subjective visual vertical; T2-WI: T2-weighted imaging; WHO: World Health Organization

\section{Declarations}

\section{ACKNOWLEDGEMENT}

1. Acknowledgements: none.

2. Financial support and sponsorship:

Funding: This work was supported by the Chang Gung Memorial Hospital, Linkou (grant CMRPG3K1161).

Author contribution: K.-T.C. developed the hypothesis. K.-T.C., S.-Y.H. and Y.-J.C. designed the paradigm. K.-T.C. and Y.-J.C. analyzed data with support from S.Y.H. K.-T.C., S.-Y.H. and Y.-J.C. wrote the manuscript, with substantial support from all authors.

Data availability: none

Conflict of interest: all authors declare no financial, consultant, institutional and other relationships that might lead to bias.

DISCLOSURES The authors have nothing to disclose.

\section{References}

1. Baier B, Conrad J, Stephan T, Kirsch V, Vogt T, Wilting J et al (2016) Vestibular thalamus: Two distinct graviceptive pathways. Neurology 86:134-140

2. Brandt T, Dieterich M (1994) Vestibular syndromes in the roll plane: topographic diagnosis from brainstem to cortex. Ann Neurol 36:337-347

3. Brandt T, Dieterich M, Danek A (1994) Vestibular cortex lesions affect the perception of verticality. Ann Neurol 35:403-412

4. Curiel M, Granel B, Chaumoitre K, Bagneres D, Rossi P, Demoux AL et al (2009) [A case of astasia abasia]. Rev Med Interne 30:174-175

5. de Pablo-Fernandez E, Villarejo A, Dominguez-Gonzalez C, Hidalgo FS, Callero EC (2009) Astasia, asymmetrical asterixis and pretectal syndrome in thalamo-mesencephalic hemorrhage. Clin Neurol Neurosurg 111:766-767

6. Diehl B, Dinner DS, Mohamed A, Najm I, Klem G, LaPresto E et al (2000) Evidence of cingulate motor representation in humans. Neurology 55:725-728

7. Dieterich M, Brandt T (2008) Functional brain imaging of peripheral and central vestibular disorders. Brain 131:2538-2552

8. Dieterich M, Brandt T (2019) Perception of Verticality and Vestibular Disorders of Balance and Falls. Front Neurol 10:172

9. Dieterich M, Brandt T (1993) Thalamic infarctions: differential effects on vestibular function in the roll plane (35 patients). Neurology 43:1732-1740

10. Elwischger K, Rommer P, Prayer D, Mueller C, Auff E, Wiest G (2012) Thalamic astasia from isolated centromedian thalamic infarction. Neurology 78:146147

11. Guillery RW (1995) Anatomical evidence concerning the role of the thalamus in corticocortical communication: a brief review. J Anat 187(3):583-592

12. Hatanaka N, Tokuno H, Hamada I, Inase M, Ito Y, Imanishi M et al (2003) Thalamocortical and intracortical connections of monkey cingulate motor areas. J Comp Neurol 462:121-138

13. Karnath HO, Ferber S, Dichgans J (2000) The neural representation of postural control in humans. Proc Natl Acad Sci U S A. 97:13931-13936

14. Karnath HO, Ferber S, Dichgans J (2000) The origin of contraversive pushing: evidence for a second graviceptive system in humans. Neurology 55:12981304

15. Karnath HO, Johannsen L, Broetz D, Kuker W (2005) Posterior thalamic hemorrhage induces "pusher syndrome". Neurology 64:1014-1019

16. Kataoka H, Sugie K, Kohara N, Ueno S (2006) Novel representation of astasia associated with posterior cingulate infarction. Stroke 37:e3-e5

17. Kausar H, Antonios N (2013) Combined thalamic ptosis and astasia. J Clin Neurosci 20:1471-1474

18. Kim JH, Kim S, Lee DH, Lee TK, Sung KB (2015) Isolated axial lateropulsion with ipsilesional subjective visual vertical tilt in caudal lateral medullary infarction. J Vestib Res 25:41-45

19. Kirsch V, Keeser D, Hergenroeder T, Erat O, Ertl-Wagner B, Brandt T et al (2016) Structural and functional connectivity mapping of the vestibular circuitry from human brainstem to cortex. Brain Struct Funct 221:1291-1308

20. Kumral E, Kocaer T, Sagduyu A, Sirin H, Toygar A, Evyapan D et al (1995) [Callosal infarction after bilateral occlusion of the internal carotid arteries with hemineglect syndrome and astasia-abasia]. Rev Neurol (Paris) 151:202-205

21. Laroche C, Buge A, Escourolle R, Caquet R, Festal G, Rancurel G (1976) ["Astasia-abasia," unilateral left-sided apraxia, and touch disorders in an astrocytoma of the corpus callosum. A clinico-pathological report]. Ann Med Interne (Paris) 127:1-10

22. Lee PH, Lee JH, Joo US (2005) Thalamic infarct presenting with thalamic astasia. Eur J Neurol 12:317-319 
23. Lopez C, Blanke O (2011) The thalamocortical vestibular system in animals and humans. Brain Res Rev 67:119-146

24. Masdeu JC, Alampur U, Cavaliere R, Tavoulareas G (1994) Astasia and gait failure with damage of the pontomesencephalic locomotor region. Ann Neurol 35:619-621

25. Masdeu JC, Gorelick PB (1988) Thalamic astasia: inability to stand after unilateral thalamic lesions. Ann Neurol 23:596-603

26. Mittelstaedt H (1998) Origin and processing of postural information. Neurosci Biobehav Rev 22:473-478

27. Okun MS, Koehler PJ (2007) Paul Blocq and (psychogenic) astasia abasia. Mov Disord 22:1373-1378

28. Paus T (2001) Primate anterior cingulate cortex: where motor control, drive and cognition interface. Nat Rev Neurosci 2:417-424

29. Rissardo JP, Caprara ALF (2019) Isolated astasia with anterior corpus callosum stroke. Neurol India 67:613

30. Russo GS, Backus DA, Ye S, Crutcher MD (2002) Neural activity in monkey dorsal and ventral cingulate motor areas: comparison with the supplementary motor area. J Neurophysiol 88:2612-2629

31. Satow T, Komuro T, Kobayashi A (2014) Caudal cingulate infarction manifesting astasia. Case Rep Neurol 6:14-17

32. Song IU, Kim JS, An JY, Kim YI, Lee KS (2007) Co-occurrence of astasia and unilateral asterixis caused by acute mesencephalic infarction. Eur Neurol 57:106-108

33. Takahashi K, Osaka A, Tsuda H, Ogasawara H (2017) Isolated astasia caused by a localized infarction in the suprathalamic white matter. J Gen Fam Med 18:275-278

34. Ticini LF, Klose U, Nagele T, Karnath HO (2009) Perfusion imaging in Pusher syndrome to investigate the neural substrates involved in controlling upright body position. PLoS ONE 4:e5737

35. Wada Y, Nishimura Y (2010) : Isolated astasia in acute infarction of the supplementary-motor area. BMJ Case Rep 2010

36. Wilke M, Dechent P, Bahr M (2017) Sarcoidosis Manifestion Centered on the Thalamic Pulvinar Leading to Persistent Astasia. Mov Disord Clin Pract 4:898-900

37. Zhang J, Xing S, Li J, Chen L, Chen H, Dang C et al (2015) Isolated astasia manifested by acute infarct of the anterior corpus callosum and cingulate gyrus. J Clin Neurosci 22:763-764

38. Zwergal A, Buttner-Ennever J, Brandt T, Strupp M (2008) An ipsilateral vestibulothalamic tract adjacent to the medial lemniscus in humans. Brain 131:2928-2935

\section{Figures}




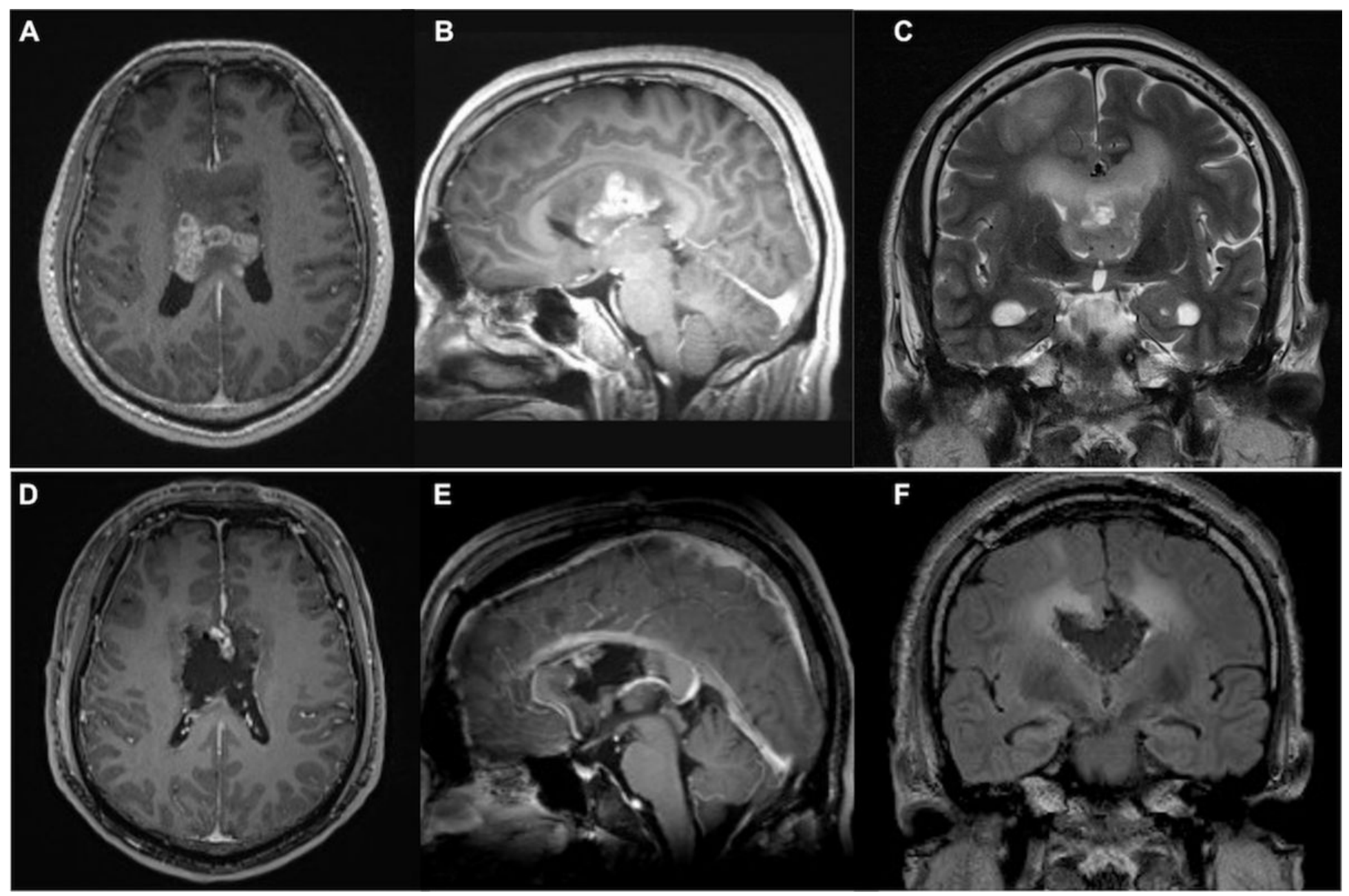

\section{Figure 1}

Pre- and postoperative brain MRI. A large butterfly glioma arising from body of corpus callosum (CC) with heterogeneous enhancement (A,B) and T2 high signal extended bilaterally through interhemispheric fibers was shown. A enlarged bilateral temporal horns (C) indicated obstructive hydrocephalus induced by an occlusion of Foramen of Monro bilaterally. The postoperative MRI showed a complete removal of contrast enhancing CC tumor (D-F) with a residual T2 high signal area (F) and resolution of obstructive hydrocephalus (F). 


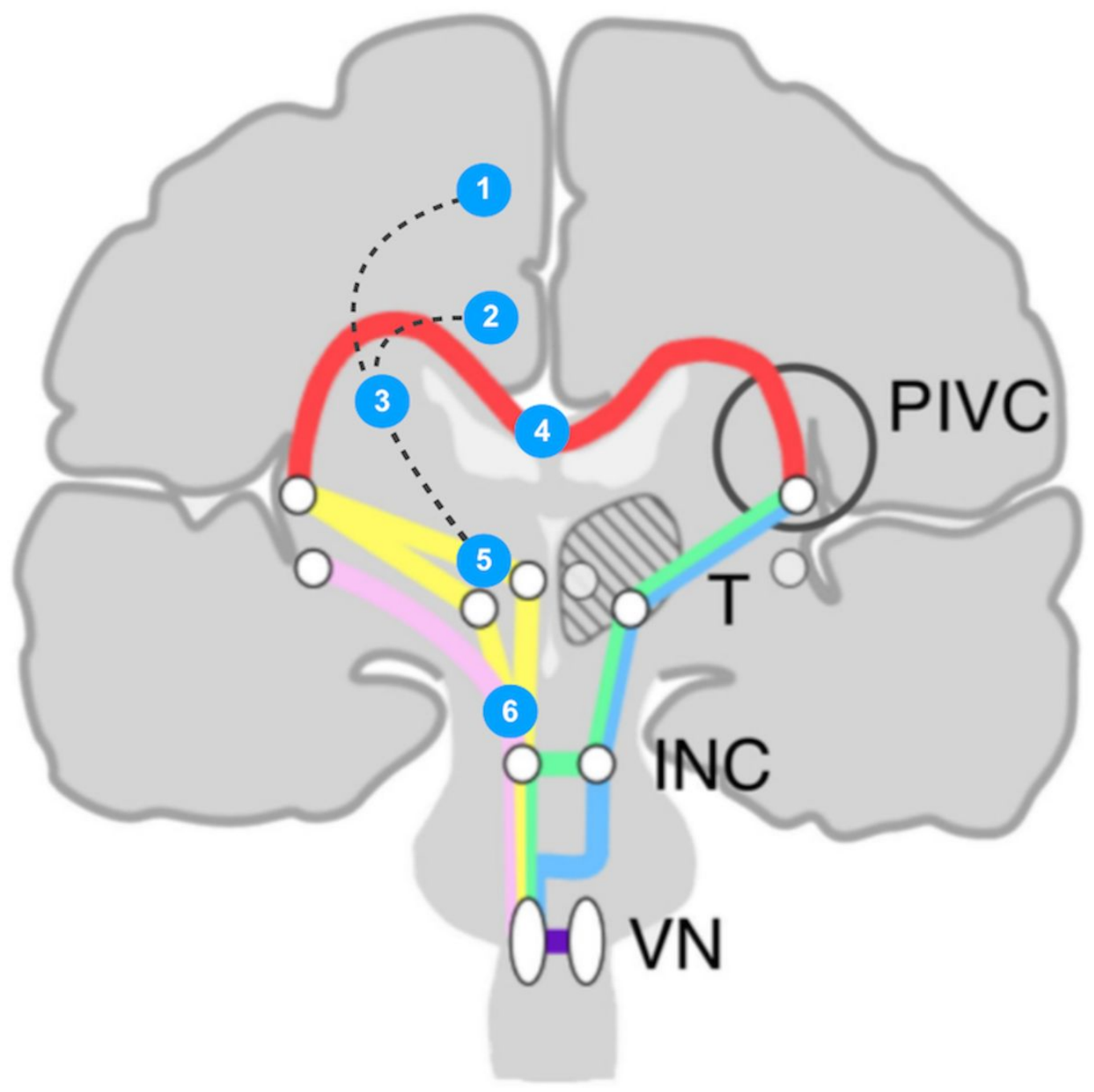

Figure 2

An illustration of cases with astasia in English literature on the schema of vestibular rope ladder system. To simplify, all 26 cases are presented by numbers at different anatomical structures and are shown ipsilaterally. 1: supplementary motor area $(n=1)$; 2 : cingulate gyrus $(n=3) ; 3$ : suprathalamic white matter $(n=1)$; 4: corpus callosum $(n=1) ; 5$ : thalamus $(n=17) ; 6$ : mesencephalon $(n=3)$. The rope ladder system demonstrates the basic network of vestibular system. PIVC: parietal insular vestibular cortex; T: thalamus; INC: interstitial nucleus of Cajal; VN: vestibular nuclei. (adapted and modified from Kirsch et al., 2015 19, with permission) 